Article

\title{
Ginsenoside Compound K Induces Adult Hippocampal Proliferation and Survival of Newly Generated Cells in Young and Elderly Mice
}

\author{
Jung-Mi Oh ${ }^{1,2,+}$, Jae Hoon Jeong ${ }^{1,+}$, Sun Young Park ${ }^{1,2}$ and Sungkun Chun ${ }^{1,2, *(D)}$ \\ 1 Department of Physiology, Chonbuk National University Medical School, Jeonju-si, \\ Jeollabuk-do 54907, Korea; biojmi@jbnu.ac.kr (J.-M.O.); jjh8690624@gmail.com (J.H.J.); \\ qirsjm@naver.com (S.Y.P.) \\ 2 Brain Korea 21 Plus Program, Chonbuk National University Medical School, Jeonju-si 54907, Korea \\ * Correspondence: sungkun.chun@jbnu.ac.kr; Tel.: +82-63-270-4290 \\ + These authors contributed equally.
}

Received: 29 February 2020; Accepted: 21 March 2020; Published: 23 March 2020

\begin{abstract}
Cognitive impairment can be associated with reduced adult hippocampal neurogenesis, and it may contribute to age-associated neurodegenerative diseases such as Alzheimer's (AD). Compound $\mathrm{K}(\mathrm{CK})$ is produced from the protopanaxadiol (PPD)-type ginsenosides $\mathrm{Rb} 1, \mathrm{Rb} 2$, and Rc by intestinal microbial conversion. Although $\mathrm{CK}$ has been reported as an inducing effector for neuroprotection and improved cognition in hippocampus, its effect on adult neurogenesis has not been explored yet. Here, we investigated the effect of CK on hippocampal neurogenesis in both young (2 months) and elderly (24 months) mice. CK treatment increased the number of cells co-labeled with 5-ethynyl-2'-deoxyuridine (EdU) and proliferating cell nuclear antigen (PCNA); also, Ki67, specific markers for progenitor cells, was more expressed, thus enhancing the generation of new cells and progenitor cells in the dentate gyrus of both young and elderly mice. Moreover, CK treatment increased the number of cells co-labeled with EdU and NeuN, a specific marker for mature neuron in the dentate gyrus, suggesting that newly generated cells survived and differentiated into mature neurons at both ages. These findings demonstrate that CK increases adult hippocampal neurogenesis, which may be beneficial against neurodegenerative disorders such as AD.
\end{abstract}

Keywords: ginsenoside CK; neurogenesis; cell proliferation; neuroprotection

\section{Introduction}

Since adult hippocampal neurogenesis in the dentate gyrus [1] has first been reported, it has been considered a main contributor to age-related cognitive impairments [2] and to neurodegenerative diseases such as Alzheimer's disease (AD) [3]. Aging leads to several symptoms, such as inflammation-induced brain metabolic changes, neurovascular defects, memory loss, and increased anxiety level in mice [4]. Furthermore, aging both reduces adult hippocampal neurogenesis $[5,6]$ and increases the risk factors for AD [7-9]. Indeed, age-dependent neurogenesis reduction [5,10,11] leads to decreased learning and memory function [12]. Therefore, any therapy aiming to increase adult hippocampal neurogenesis could be an important strategy to mitigate age-related neurodegenerative diseases such as AD.

Ginsenoside compound K (CK) is conversion from protopanaxadiol (PPD)-type ginsenosides $\mathrm{Rb} 1, \mathrm{Rb} 2$, and $\mathrm{Rc}$ by intestinal microbiota [13]. Previous researches reported that CK exhibits beneficial pharmacological effects, including antidiabetic [14], anti-inflammatory [15], anticancer [16], and antiaging [17] activity. Recent evidences suggest that CK has a role in neuroprotection and in cognitive improvement. For instance, CK protects neurons in the stroke mouse model by reducing 
microglial activation through its anti-inflammatory activity [18]. Also, chemotherapy-induced cognitive impairment was mitigated by CK administration in mice [19]. In vascular dementia rats, CK cleared the beta-amyloid deposition, resulting in the attenuation of both neuronal damage and cognitive deficits [20]. In addition, $10 \mathrm{mg} / \mathrm{Kg}$ CK was successfully used in mice to reduce scopolamine-induced memory impairment and negative effects of reactive oxygen species via the induction of Nrf2-mediated antioxidant enzyme [21]. Although previous studies regarding the neuroprotective beneficial effects of CK have been reported, the direct evidence regarding the effect of CK on adult hippocampal neurogenesis is still unknown. Hence, in this study, we investigated the potential of CK to modulate adult hippocampal neurogenesis.

\section{Materials and Methods}

\subsection{Animals}

All mouse care and experimental procedures were approved by the Institutional Animal Care and Use Committee of the Chonbuk National University (permit number: CBNU-2018-042, Approval date: 05 June 2018). Two-month-old (-mo) and 24-mo male mice were purchased from Jackson Laboratories (Bar Harbor, ME, USA). Animals were kept grouped in cages at $22{ }^{\circ} \mathrm{C}$ with a 12:12-h light-dark cycle and fed a standard chow diet with ad libitum access to water.

\subsection{Compound K Administration}

Ginsenosides compound K was obtained from the laboratory of Ace EMzyme, Hankyung National University, South Korea. Compound K (CK) was dissolved in 100\% dimethyl sulfoxide (DMSO) and then diluted daily in 2-hydroxypropyl-cyclodextrin (cat. no. H5784; Invitrogen). For 3 consecutive days, 2-mo and 24-mo mice were injected intraperitoneally either diluted CK $(5,10$, or $15 \mathrm{mg} / \mathrm{Kg})$ or vehicle $(0 \mathrm{mg} / \mathrm{Kg})$.

\subsection{EdU Administration}

To determine the cell proliferation rate induced by $\mathrm{CK}$, on the last $\mathrm{CK}$ administration day, all mice received an intraperitoneal injection of phosphate-buffered saline (PBS)-EdU (100 mg/Kg, ab146186, Abcam, Cambridge, Massachusetts, UK). Mice were then sacrificed after $24 \mathrm{~h}$. For neuronal survival analysis, EdU was injected for 3 consecutive days after the last $\mathrm{CK}$ injection, and all remaining mice were sacrificed after 4 weeks.

\subsection{Perfusion}

At the end of the experiment, all mice were perfused with $0.1 \mathrm{M}$ PBS containing heparin (1000 u/mL; cat. no. H3393; Sigma-Aldrich; Merck KGaA, Darmstadt, Germany) and prefixed with $4 \%$ paraformaldehyde (PFA) in $0.1 \mathrm{M}$ PBS. All brains were postfixed in a 4\% PFA solution for $24 \mathrm{~h}$ at $4{ }^{\circ} \mathrm{C}$, dehydrated in a $30 \%$ sucrose solution at $4{ }^{\circ} \mathrm{C}$ for $72 \mathrm{~h}$, and immediately frozen at $-80^{\circ} \mathrm{C}$. Coronal sections $(40 \mu \mathrm{m})$ were cut with a cryostat (Leica CM 1860, Leica Biosystems Inc., Chicago, IL, USA), and slices were stored in cryoprotectant ( $25 \%$ ethylene glycol and $25 \%$ glycerin) in $0.05 \mathrm{M}$ phosphate buffer at $-20^{\circ} \mathrm{C}$.

\subsection{Immunohistochemistry}

Every sixth serial section was tested for cell proliferation with the Click-iT EdU Cell Proliferation Kit for Imaging, Alexa Fluor 488 dye (cat. no. C10337; Invitrogen, Gaisburg, MD, USA) according to the manufacturer's instructions. Briefly, the free-floating sections were washed 3 times in $0.1 \mathrm{M}$ PBS containing $3 \%$ bovine serum albumin (BSA), permeabilized with $0.5 \%$ Triton-X 100 in PBS for 20 min, and rinsed with 3\% BSA in PBS. Then, the sections were incubated with the Click-iT reaction buffer for $30 \mathrm{~min}$ at room temperature (RT), washed 3 times in PBS, mounted on a slide-glass using Vectashield antifade mounting medium (cat. no. H-1000; Vector Laboratories, Burlingame, CA, USA), and covered 
with a coverslip. For EdU and immunohistochemistry double labeling, the sections were incubated in $1 \times$ Target Retrieval Solution (Dako, cat\# S1699) at $95{ }^{\circ} \mathrm{C}$ for $5 \mathrm{~min}$ prior to the EdU staining procedure. After EdU staining, sections were incubated in blocking solution (5\% BSA and 0.1\% Triton X-100 in PBS) for $2 \mathrm{~h}$ at RT and then incubated with anti-proliferating cell nuclear antigen (anti-PCNA) (1:1000; cat. no. 2586; Cell Signaling Technology, Danvers, MA, USA), anti-Ki67 (1:1000; cat. no. ab15580; Abcam), or anti-NeuN (1:1000; cat. no. 24307; Cell Signaling Technology) antibodies for $24 \mathrm{~h}$ at $4{ }^{\circ} \mathrm{C}$. Sections were then washed 3 times in PBS and incubated with Alexa 594 anti-mouse IgG (1:1000; cat. no. ab150116; Abcam) or Alexa 594 anti-rabbit IgG (1:1000; cat. no. ab150080; Abcam) for 2 h at RT. Tissues were washed, dried, and mounted with mounting medium. Images were acquired using a Zeiss LSM 880 super resolution confocal microscope.

\subsection{Immunoblotting}

Radioimmunoprecipitation assay (RIPA) buffer (cat. no. R2002; Biosesang, Seongnam-si, South Korea) containing proteinase inhibitors (cat. no. G652A; Promega, South Korea) was used to obtain total lysates from the hippocampus of 2-mo and 24-mo C57BL/6 mice injected with vehicle or CK. Total lysates $(20 \mu \mathrm{g})$ were separated on 12\% SDS-PAGE gels and transferred to polyvinylidene fluoride (PVDF) membranes and then kept in 5\% skim milk blocking buffer for $2 \mathrm{~h}$ at RT. Anti-brain-derived neurotrophic factor (anti-BDNF) (1:1000; cat. no. ab108319; Abcam), anti-pAkt (Ser473) (1:1000; cat. no. 4060; Cell Signaling Technology), anti-Akt (1:1000; cat. no. 9272; Cell Signaling Technology), anti-pERK1/2 (1:1000; cat. no. 9101; Cell Signaling Technology), anti-ERK1/2 (1:1000; cat. no. 4696; Cell Signaling Technology), and anti-GAPDH (1:5000; cat. no. AP0066; Bioworld Technology) antibodies diluted in TBST (Tris buffered saline Tween 20) buffer containing 5\% BSA, which was used for the membranes' incubation for $24 \mathrm{~h}$ at $4{ }^{\circ} \mathrm{C}$. The membranes were then washed in TBST buffer and probed with anti-rabbit IgG, horseradish peroxidase (HRP)-linked or anti-mouse IgG, HRP-linked secondary antibodies (1:3000; cat. no. 7074 and 7076; Cell Signaling Technology) for $2 \mathrm{~h}$ at RT. All membranes were washed in TBST buffer and developed using Clarity Western ECL Substrate (cat. no. 1705060; BIO RAD, Hercules, CA, USA).

\subsection{Quantitative Reverse Transcription PCR}

For qRT-PCR analysis of neurotrophin 3 (NT3) and brain-derived neurotrophic factor (BDNF) genes, total RNA was isolated from hippocampus using the Trizol reagent (Thermo Fisher Scientific, Inc., 15596026) and then first-strand cDNA was synthesized using GoScript Reverse Transcription System (cat. no. A5001; Promega). Real-time qPCR was performed with 7900 HT fast Real-Time PCR System (Applied Biosystems) using SYBR Green I Master Mix (cat. no. RT501M; Enzynomics). Each qPCR reaction was prepared in a final volume of $10 \mu \mathrm{L}$, containing $2 \mu \mathrm{L}$ cDNA and $5 \mu \mathrm{L}$ of SYBR Green Master mix with a different primer pair $(1 \mu \mathrm{L}, 10 \mathrm{pmole} / \mu \mathrm{L})$. Beta-actin was used as an internal control for the quantification of each sample. The primer pairs employed are F5'-CAAAGGGATCGTTGGAGGTGA-3' and R5' - GTTCGGTCAT TCAGTCTCGC-3' for NT3, F5'-TCATACTTCGGTTGCATGAAGG-3' and R5'-AGACCTCTC GAACCTGCCC-3' for BDNF, and F5'-CCTGACAGACTACCTCATGAAG-3' and R5' - CCATC TCTTGCTCGAAGTCTAG-3' for beta-actin. Relative gene expression was determined using the ${ }^{\Delta \Delta} \mathrm{C}$ method. Relative mRNA expression levels were presented as the fold change compared with the 2-mo mice vehicle group.

\subsection{Statistical Analysis}

All statistics were performed with GraphPad Prism (version 5.01.) for windows (Graphpad Software, San Diego, CA, USA). Data were expressed as mean \pm standard error of the mean (SEM). Statistical significance was assessed using an unpaired t-test. Results with $p<0.05$ were considered significant. 


\section{Results}

\subsection{CK Increases the Number of Newly Born Cells in the Dentate Gyrus}

We first purified compound K (>97\%, molecular structure in Figure 1A) by acid-heat treatment of PPD-type ginsenoside extracts from Korean ginseng (Panax ginseng). To determine the effect of $\mathrm{CK}$ on cell proliferation in young and elderly mice, both mice groups were injected with various concentration of $\mathrm{CK}(0 \mathrm{mg} / \mathrm{Kg}, 5 \mathrm{mg} / \mathrm{Kg}, 10 \mathrm{mg} / \mathrm{Kg}$, and $15 \mathrm{mg} / \mathrm{Kg}$ ) for 3 consecutive days and then with EdU (Figure 1b). Twenty-four h after EdU injection, all mice were transcardially perfused and the brain was sectioned for histological study using a cryostat $(40 \mu \mathrm{m})$.

(a)

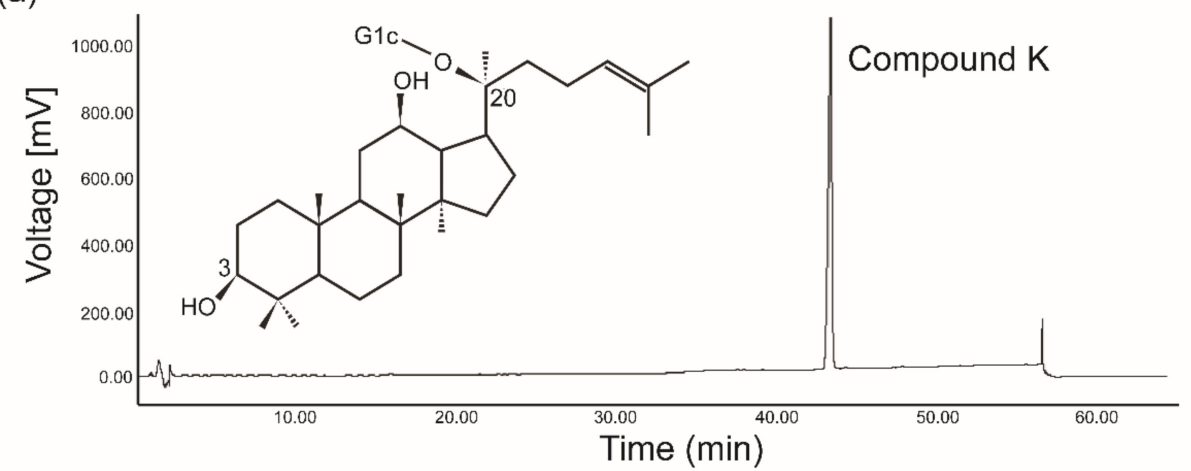

(b)

1. To measure the proliferation rate of new born cells.

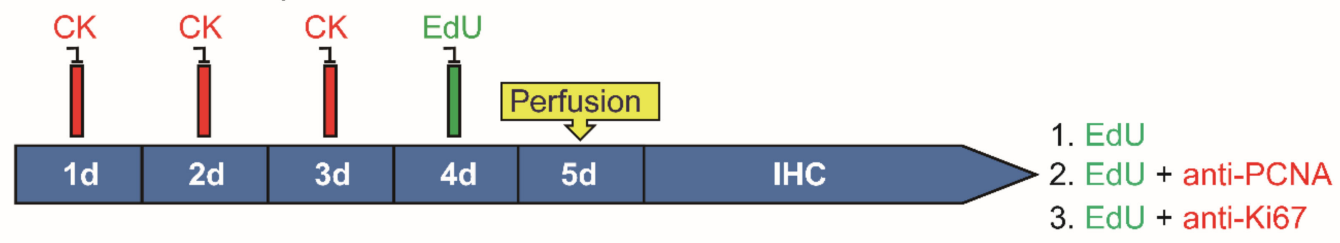

2. To measure the survival rate of new born cells.

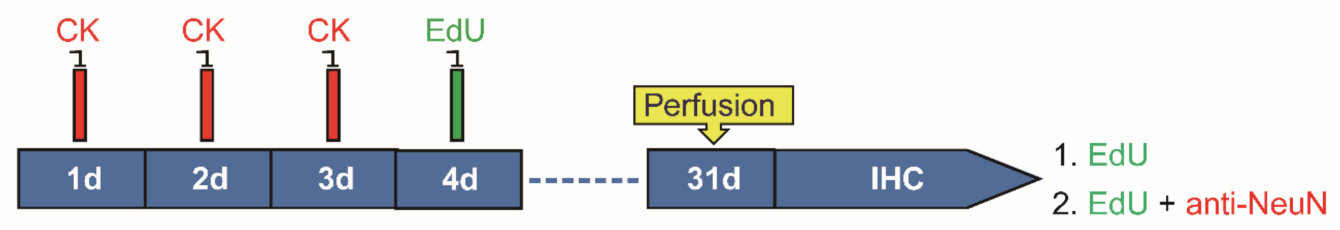

Figure 1. (a) Chemical structure of Compound $K(C K)$ and high-performance liquid chromatography (HPLC) analysis of the transformation of CK: The chromatographic peak was identified by comparison with the reference compounds. (b) Experimental design. In experiment 1: mice were injected with 5-ethynlyl-2'-deoxyuridine (EdU, $100 \mathrm{mg} / \mathrm{Kg}$ ) once after 3 consecutive $\mathrm{CK}$ intraperitoneal injections and sacrificed on day 5 or on day 31 for proliferation or survival studies, respectively. Antibodies for EdU, proliferating cell nuclear antigen (PCNA), and Ki67 were used to measure the proliferation of newly born cells, while antibodies for EdU and NeuN were used to measure the survival rate of newly born cells.

The total number of EdU-incorporated cells was counted in the subgranular zone of the dentate gyrus. The CK dose-dependently increased the number of EdU-incorporated newborn cells in the dentate gyrus of young mice (Figure 2a,c). However, the production of new cells in 24-mo mice was significantly increased only with $15 \mathrm{mg} / \mathrm{Kg} \mathrm{CK}$ (Figure $2 \mathrm{~b}, \mathrm{c}$ ). These results show that the number of new cells does decrease by aging, but this trend could be slowed by treatments with more concentrated ginsenoside $\mathrm{CK}$. 


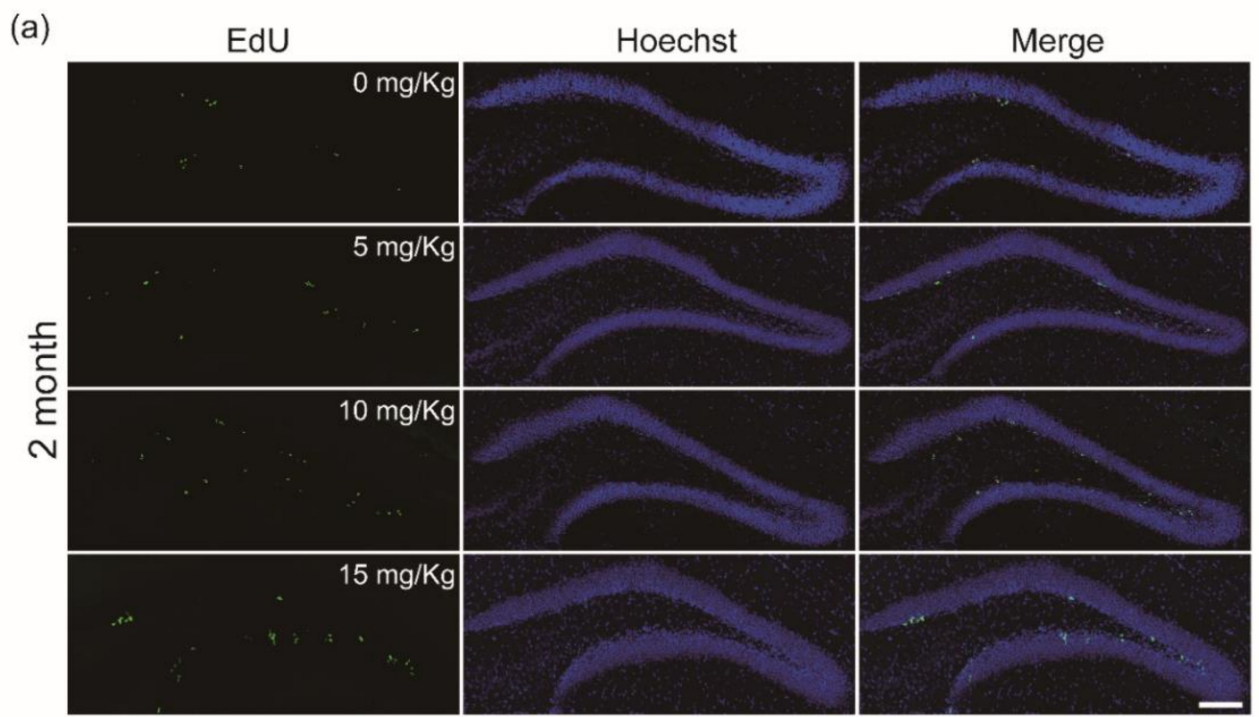

(b)

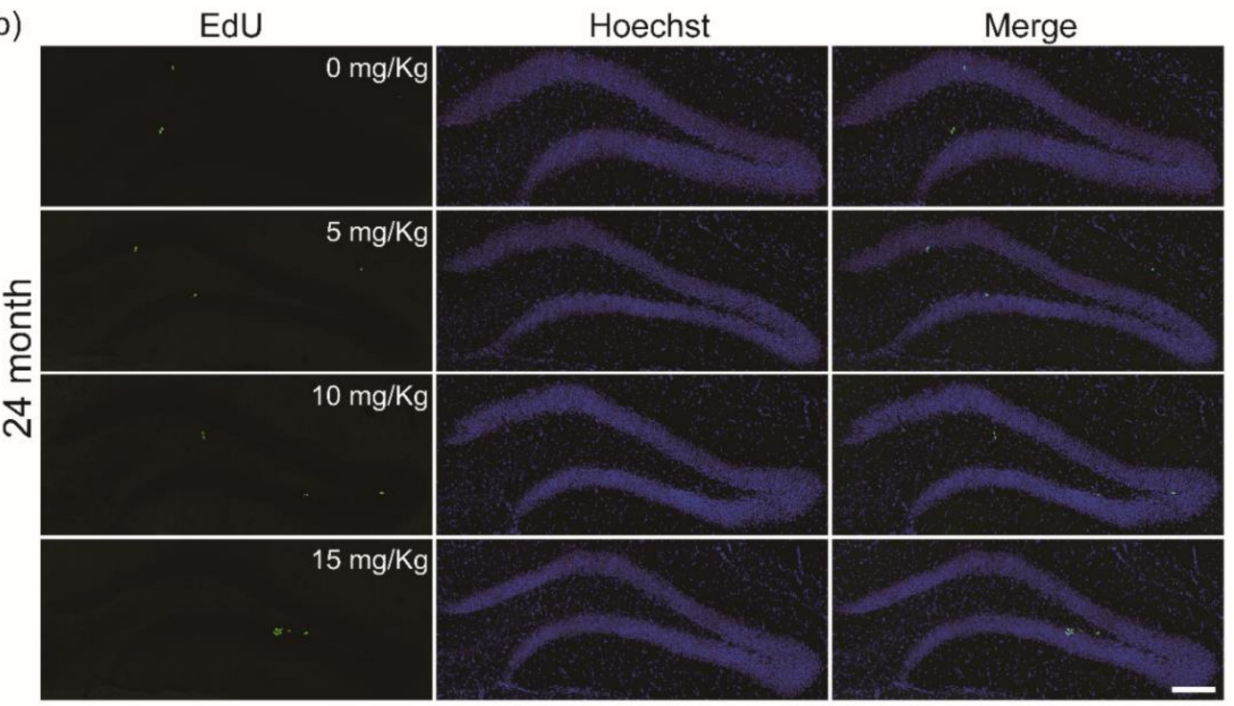

(c)

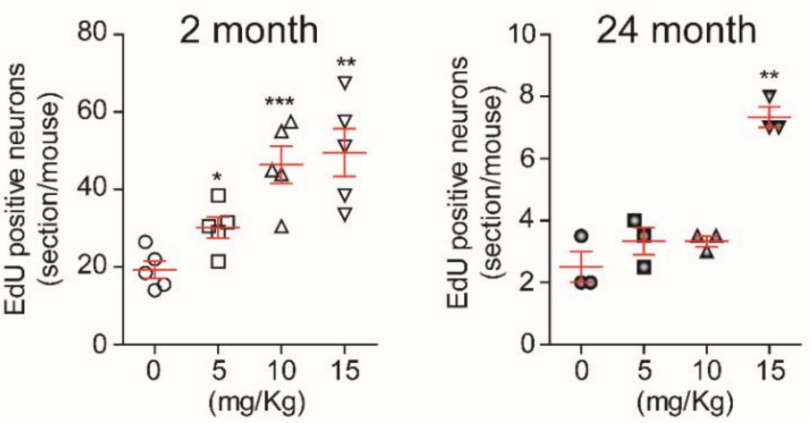

Figure 2. Compound $\mathrm{K}(\mathrm{CK})$ induces the production of new cells in the dentate gyrus (DG) of hippocampus: Images of confocal microscopy showing 5-ethynyl-2'-deoxyuridine (EdU)-labeled cells in the dentate gyrus of 2-month-old (-mo) (a) and 24-mo mice (b). All C57BL/6 mice were intraperitoneally injected with EdU ( $5 \mathrm{mg} / \mathrm{Kg}, 10 \mathrm{mg} / \mathrm{Kg}$, and $15 \mathrm{mg} / \mathrm{Kg}$ ) or vehicle for 3 consecutive days. (c) Summary plots showing that CK promotes the generation new cells in a dose-dependent manner ( $n=5$ in 2-mo; $n=3$ in 24-mo mice, respectively). All data are represented as the mean \pm standard error of the mean (SEM). ${ }^{*} p<0.05,{ }^{* *} p<0.01$, and ${ }^{* * *} p<0.001$ vs. vehicle treated groups (unpaired $t$-test). 


\subsection{CK Enhances the Proliferation of Newly Born Cells in the Dentate Gyrus}

Given that CK showed potent effects on newly born cell production in the dentate gyrus of both age groups, we next investigated its effects using double immunofluorescence staining with the anti-proliferating cell nuclear antigen (PCNA), which is a marker for cell proliferation. We found that $10 \mathrm{mg} / \mathrm{Kg} \mathrm{CK}$ significantly increased both PCNA-labeled cells and EdU-PCNA double-labeled cells in the dentate gyrus of hippocampus (Figure 3).

(a)
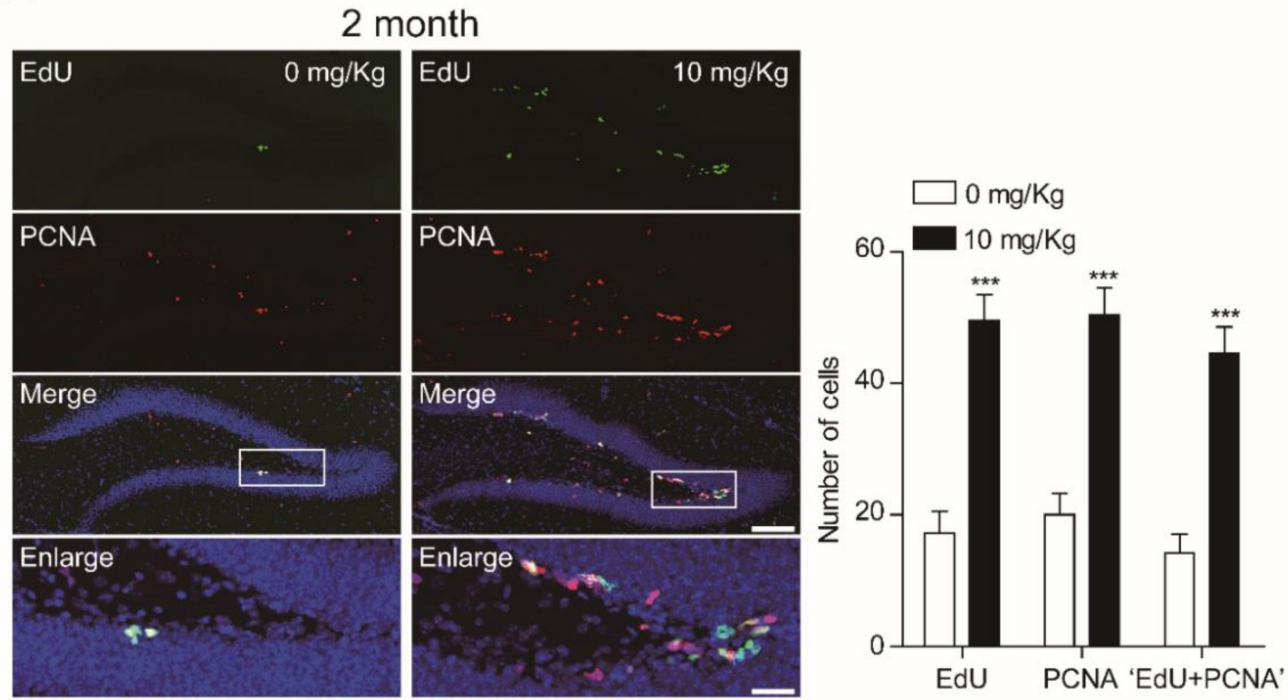

(b)

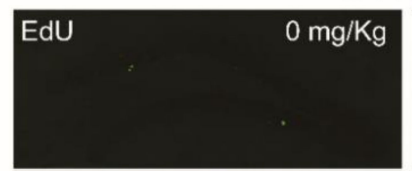

24 month
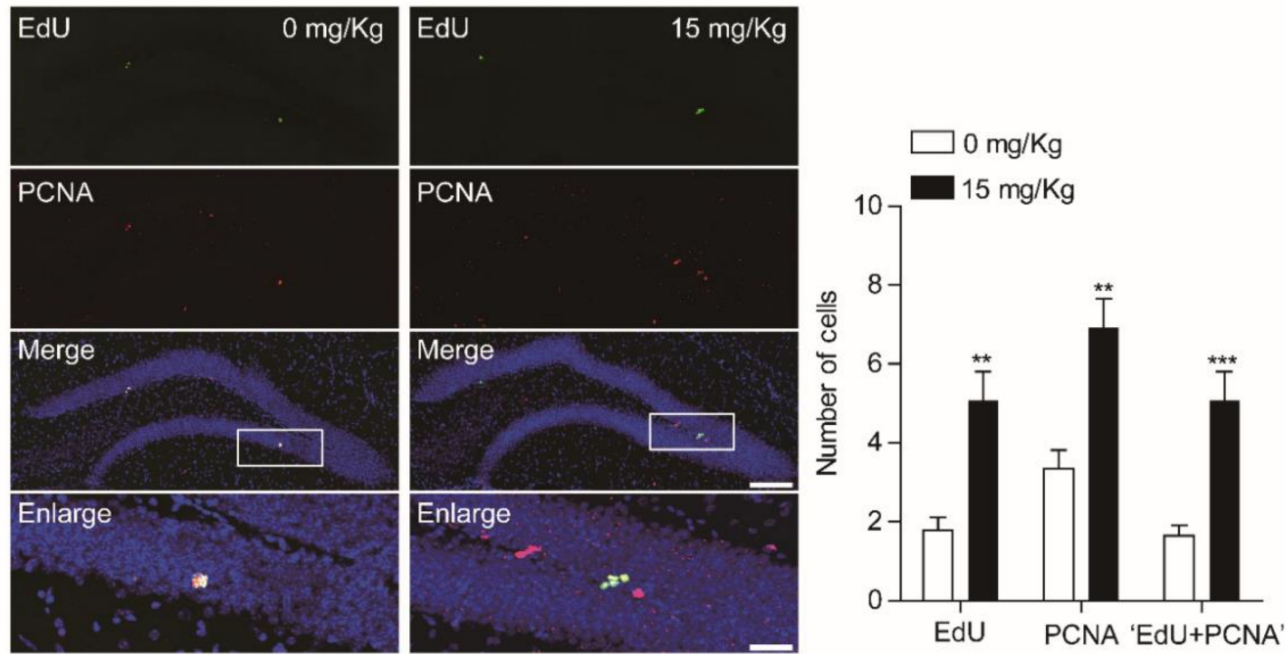

Figure 3. Compound $\mathrm{K}(\mathrm{CK})$ increases 5-ethynyl-2'-deoxyuridine (EdU)+/PCNA+ cells as well as PCNA+ cells in the DG of hippocampus. (a) Co-expression of PCNA in the EdU-labeled newborn cells in the dentate gyrus (DG) of 2 -mo mice $\left(0 \mathrm{mg} / \mathrm{Kg}, n=5 \mathrm{mice} ; 10 \mathrm{mg} / \mathrm{Kg}, n=4\right.$ mice; ${ }^{* * *} p<0.001$, unpaired $t$-test). Scale bar $=100 \mu \mathrm{m}$ (merge) or $20 \mu \mathrm{m}$ (enlarge). (b) Image of confocal microscopy showing expression of PCNA in the EdU-labeled newborn cells of DG of 24-mo mice. Plots showing that CK increases PCNA positive cells in EdU-labeled newborn cells $(0 \mathrm{mg} / \mathrm{Kg}, n=7 ; 15 \mathrm{mg} / \mathrm{Kg}, n=7$; ${ }^{* *} p<0.01,{ }^{* * *} p<0.001$, unpaired $t$-test). Scale bar $=100 \mu \mathrm{m}$ (merge) or $20 \mu \mathrm{m}$ (enlarge).

$\mathrm{Ki}-67$ is also a classic marker for cellular proliferation and is preferentially expressed during the late G1, S, G2, and M phases of the cell cycle, whereas resting, non-cycling cells (G0 phase) lack Ki-67 expression. Also, it is reported that the Ki-67 antigen is a more specific marker for cell proliferation 
than PCNA [22]. We further confirmed the effect of CK on the proliferation of newborn cells in the dentate gyrus of hippocampus. Ten $\mathrm{mg} / \mathrm{Kg} \mathrm{CK}$ significantly enhanced the Ki-67 positive cells in the dentate gyrus of hippocampus as well as Ki-67 and EdU double-positive cells (Figure 4). These results suggest that $\mathrm{CK}$ enhances the proliferation rate of newborn cells, resulting in an increase of both PCNA and Ki-67-labeled EdU-positive cells.

(a)
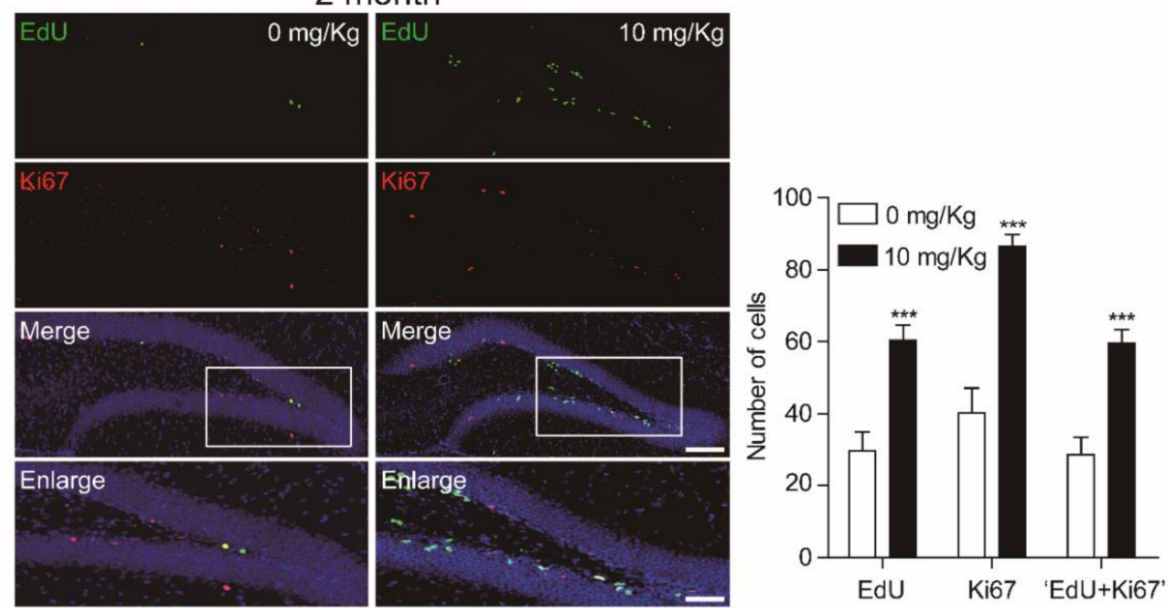

(b)
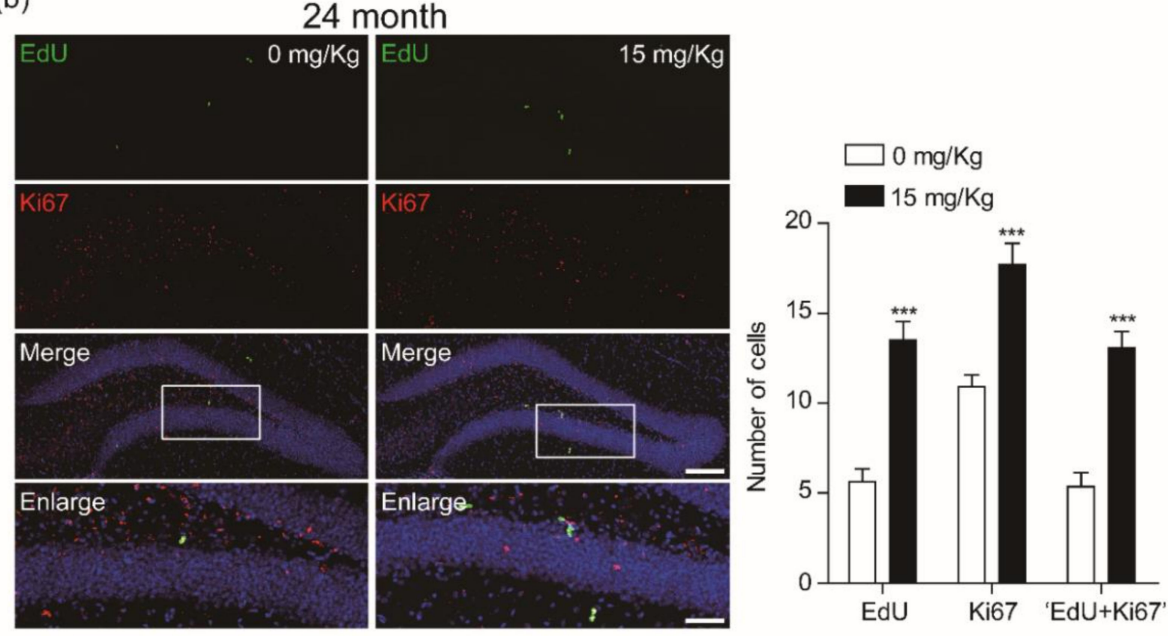

Figure 4. Compound K (CK) induces the number of co-labeled cells with 5-ethynyl-2'-deoxyuridine (EdU) incorporation and anti-Ki67 in the dentate gyrus (DG) of hippocampus. Confocal images showing EdU+/Ki67+ cells in the DG of (a) $2-\mathrm{mo}(0 \mathrm{mg} / \mathrm{Kg}, n=5 ; 10 \mathrm{mg} / \mathrm{Kg}, n=6)$ and (b) 24-mo mice $(0 \mathrm{mg} / \mathrm{Kg}$, $n=7 ; 15 \mathrm{mg} / \mathrm{kg}, n=7)$. The summary plots show quantification of positive cells for EdU, Ki67, or EdU/Ki67 in 2-mo or 24-mo mice with CK treatment. All data are represented as the mean \pm standard error of the mean (SEM). ${ }^{* * *} p<0.001$ vs. vehicle treated groups (unpaired $t$-test). Scale bar $=100 \mu \mathrm{m}$ (merge) or $20 \mu \mathrm{m}$ (enlarge).

\subsection{CK Improves Adult Hippocampal Neurogenesis by Increasing Neuronal Survival}

To investigate whether $\mathrm{CK}$ induces adult hippocampal neurogenesis through an increasing survival rate of newborn cells in the DG of hippocampus of both 2-mo and 24-mo mice, we performed immunohistochemistry for EdU and mature neuronal marker protein (NeuN) co-labeled neurons.

Both age groups showed a significant increase of EdU cells when treated with CK (Figure 5a,b). Furthermore, CK increased the proportion of EdU-labeled cells that also expressed NeuN in both 
aged mice (Figure 5a,b), indicating that CK induces not only the survival of newborn cells but also differentiation into neurons. Thus, CK seems to facilitate adult hippocampal neurogenesis.

(a)

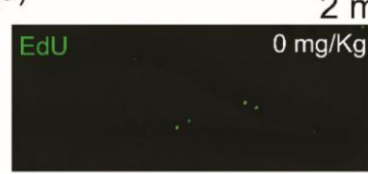

2 month
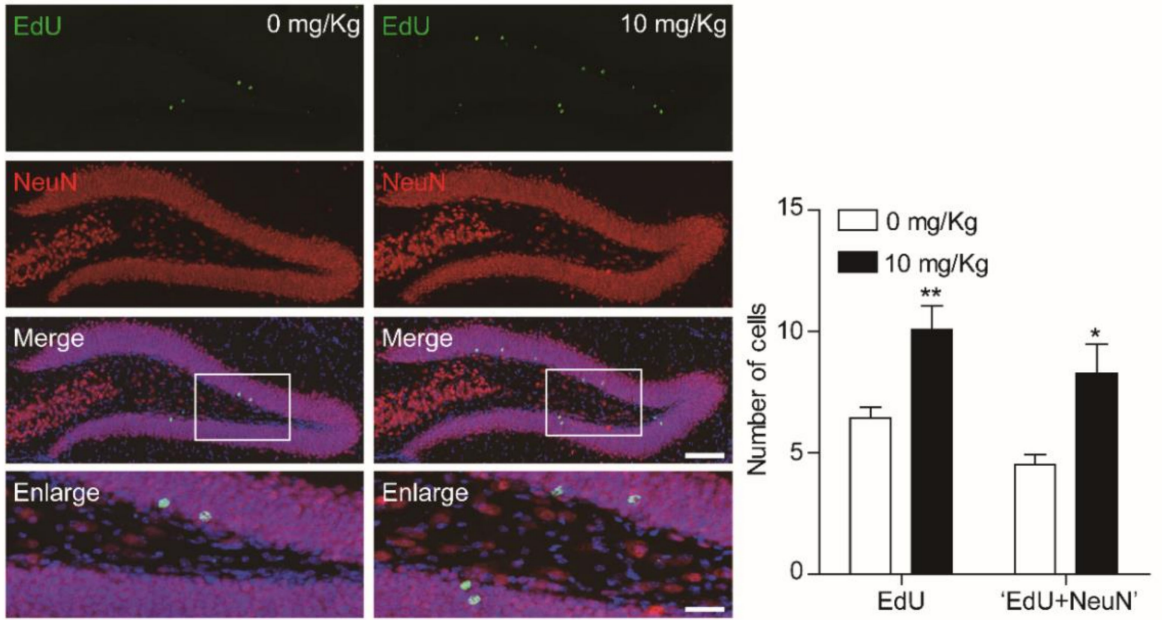

(b)

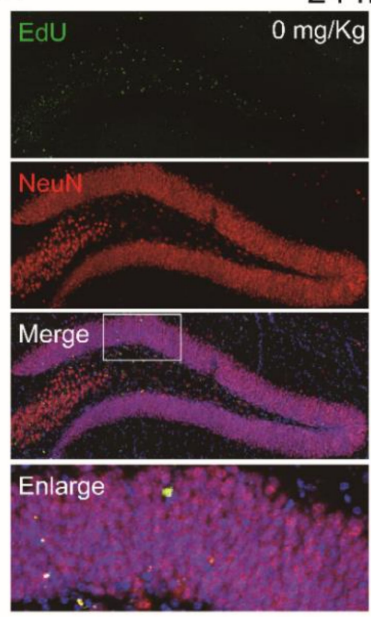

24 month
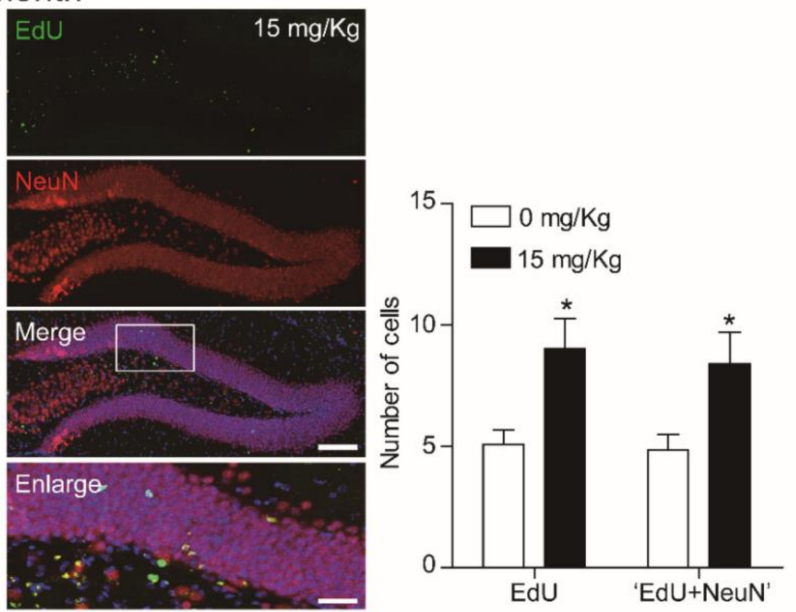

Figure 5. Compound $\mathrm{K}(\mathrm{CK})$ enhances the survival of newly generated cells in the dentate gyrus (DG) of hippocampus. Confocal images show that the survival rate of 5-ethynyl-2'-deoxyuridine (EdU)-labeled new born cells were enhanced by CK in the DG of (a) 2-mo ( $n=6$ in $0 \mathrm{mg} / \mathrm{Kg}$ and $10 \mathrm{mg} / \mathrm{Kg}$, respectively) and (b) 24-mo mice ( $n=6$ in $0 \mathrm{mg} / \mathrm{Kg} ; n=5$ in $15 \mathrm{mg} / \mathrm{Kg})$. The plots showed a significant induction in co-expression of EdU and NeuN $\left({ }^{*} p<0.05,{ }^{* *} p<0.01\right.$, unpaired $t$-test). Scale bar $=100 \mu \mathrm{m}$ (merge) or $20 \mu \mathrm{m}$ (enlarge).

\subsection{Adult Neurogenesis by CK is Mediated via BDNF Signaling}

Neurotrophic factors and growth factors are well known as potent activators of adult hippocampal neurogenesis [23]. We thus examined whether CK-induced neurogenesis is mediated by those factors. Real-time qPCR was performed to determine the expression levels of neurotrophin-3 (NT3) and brain-derived neurotrophic factor (BDNF) in the dentate gyrus of the two age groups treated with CK or with the vehicle. After 3 days of treatment, the NT3 and BDNF mRNA levels in the CK-injected mice were significantly higher than those in the vehicle-injected mice (Figure 6a). In addition, the expression level of NT3 and BDNF was reduced in vehicle-injected 24-mo mice compared with vehicle-injected 2-mo mice, but both gene expression levels after CK administration were higher than those in the vehicle-injected 2-mo mice (Figure 6a). Next, we investigated the effect of CK administration on the influence of the intracellular BDNF signaling pathway over adult hippocampal neurogenesis. The activation of BDNF 
and its downstream signaling pathway leads neurogenesis through control of neuronal proliferation and survival $[24,25]$. As observed from our qRT-PCR data, BDNF expression was significantly increased by CK administration in 2-mo mice, while in CK-injected 24-mo mice, it was comparable to that of vehicle-injected 2-mo mice (Figure 6B,C). Furthermore, $10 \mathrm{mg} / \mathrm{Kg}$ and $15 \mathrm{mg} / \mathrm{Kg}$ CK were sufficient to induce the phosphorylation of Akt and ERK1/2, which are downstream targets of the BDNF signaling pathway in 2-mo and 24-mo mice, respectively (Figure 6b,c). These results indicate that CK-induced adult hippocampal neurogenesis is mediated by the BDNF signaling pathway (Figure 7).
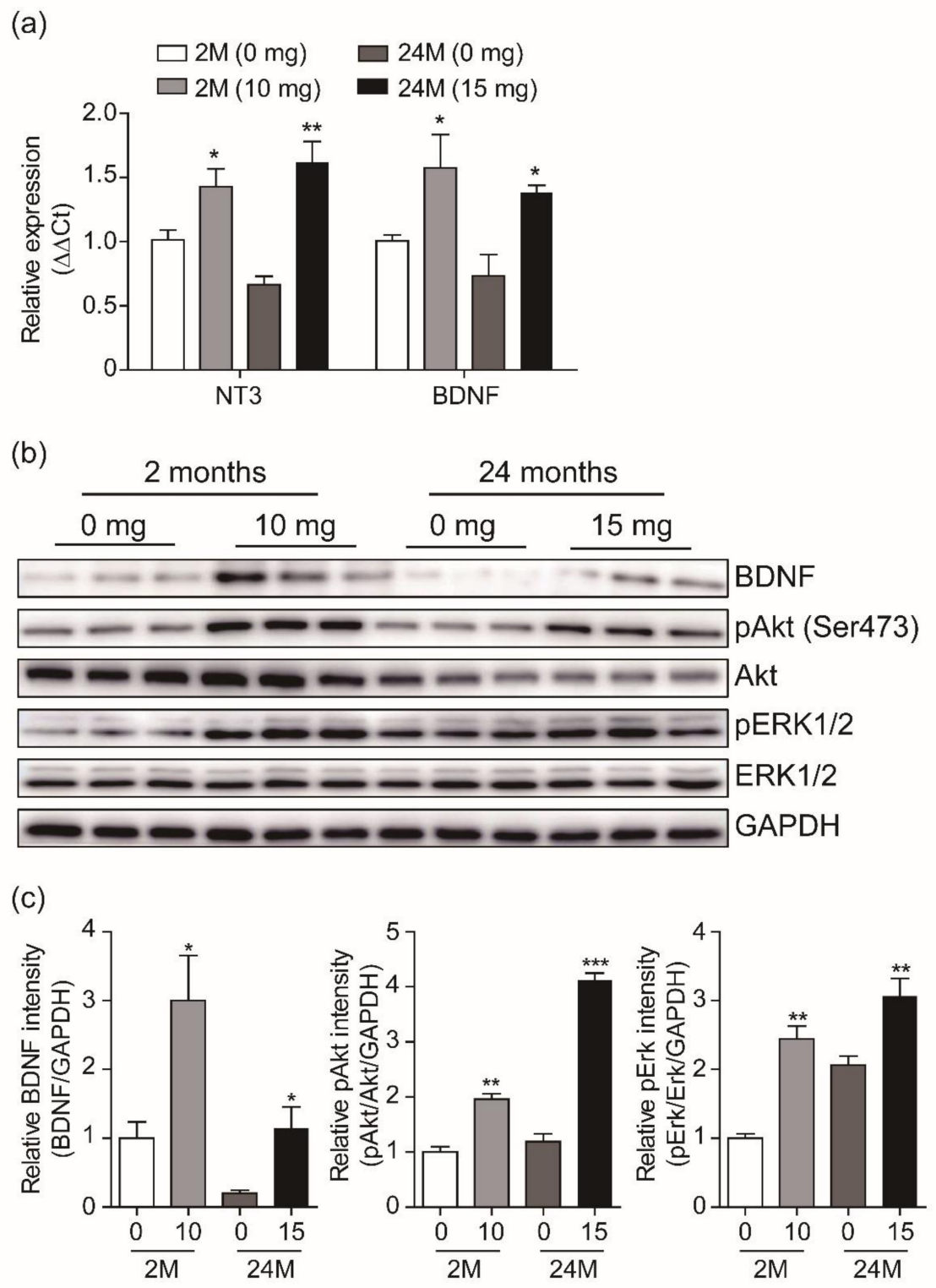

Figure 6. Beneficial effects of Compound K (CK) on adult neurogenesis is mediated via brain-derived neurotrophic factor (BDNF) signaling. (a) Summary plots showing neurotrophin-3 (NT3) and brain-derived neurotrophic factor (BDNF) mRNA expression in the dentate gyrus (DG) of hippocampus of 2-mo and 24-mo mice after CK $(10 \mathrm{mg} / \mathrm{Kg}$ or $15 \mathrm{mg} / \mathrm{Kg})$ or vehicle $(0 \mathrm{mg} / \mathrm{Kg})$ injection. Those expressions significantly increased after CK administration $\left(n=3\right.$, respectively, ${ }^{*} p<0.05,{ }^{* *} p<0.01$, unpaired $t$-test). (b) Immunoblotting of total lysates from the DG after CK or vehicle treatment of both age groups. BDNF, Akt, and ERK signaling pathways for adult neurogenesis were screened $(n=3)$. (c) Summary plots showing the immunoblotting quantification for BDNF expression and its downstream targets: CK was sufficient to increase BDNF expression and the phosphorylation of Akt and ERK1/2, which are downstream targets of $\operatorname{BDNF}\left({ }^{*} p<0.05,{ }^{* *} p<0.01,{ }^{* * *} p<0.001\right.$, unpaired $t$-test). 
(a)
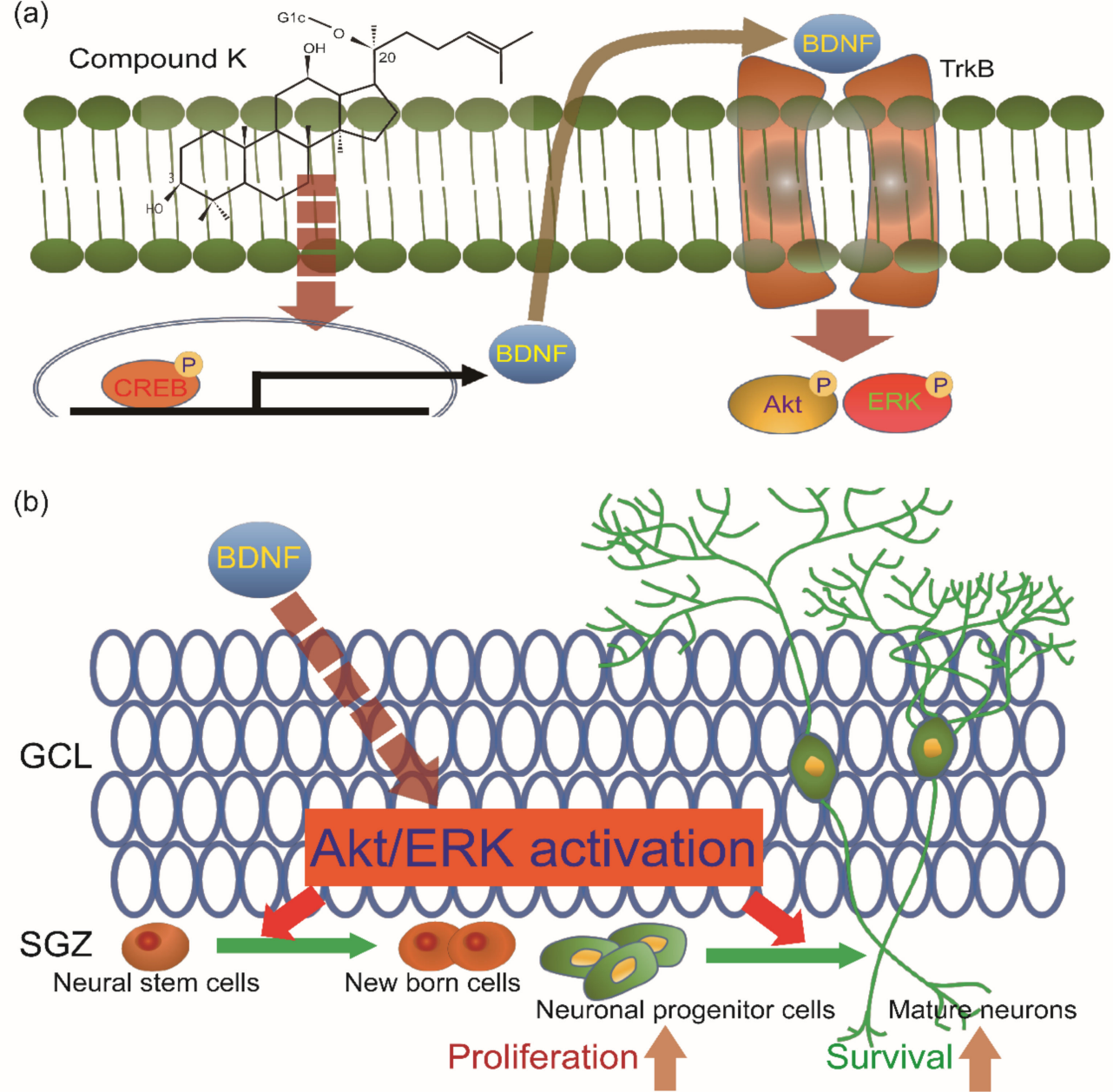

Figure 7. Schematic illustration of the proposed model: Compound $\mathrm{K}(\mathrm{CK})$ increases adult neurogenesis in the dentate gyrus (DG) of hippocampus by inducing BDNF signaling cascades. (a) CK increases the expression of BDNF and increased BDNF activates Akt and ERK signaling. (b) Activated Akt and ERK signals induced the proliferation and differentiation of newly born cells into progenitor cells and mature neurons. GCL, granule cell layer; SGZ, subgranular zone.

\section{Discussion}

In this study, we provide the first evidence that ginsenoside compound $\mathrm{K}$ has the ability to induce the production, proliferation, and survival of newborn cells through the activation of BDNF signaling. Notably, CK administration was sufficient to increase hippocampal neurogenesis even in 24-mo mice, suggesting that $\mathrm{CK}$ can contrast age-related cognitive impairment by improving adult neurogenesis.

Compound $\mathrm{K}$ is known to have a neuronal protective role following chemotherapy treatment [19]. However, there was no direct evidence for the effect of CK on adult hippocampal neurogenesis so far. The decline of adult hippocampal neurogenesis by aging contributes to cognitive impairment and is associated with age-related neurodegenerative diseases such as AD [26-28]. Furthermore, exercise and dietary energy restriction enhance the adult hippocampal neurogenesis, improve learning and memory, and protect against age-related cognitive decline and $\mathrm{AD}[26,29,30]$. Therefore, the enhancement of neurogenesis by exogenous factors could lead to novel therapeutic strategies for preventing cognitive impairment and $\mathrm{AD}$. We found that $\mathrm{CK}$ administration increased newborn cells in the dentate gyrus of 24-mo mice, resulting in more newly generated EdU cells. Also, injections of $10 \mathrm{mg} / \mathrm{Kg}$ and $15 \mathrm{mg} / \mathrm{Kg}$ CK were sufficient to induce proliferation of newborn cells in 2-mo and 24-mo mice, respectively. In addition, CK significantly enhanced the differentiation of newly generated cells in the dentate gyrus 
of hippocampus into adult neurons. The rate of neuronal survival in CK-treated 24-mo mice was similar to its rate in 2-mo mice. These results suggest that CK has the ability to facilitate adult hippocampal neurogenesis under declining neurological conditions such as age-related cognitive impairment.

Neurotrophic factors such as BDNF and growth factors including neurotrophin-3 (NT3) are important activators of adult neurogenesis [31-34]. Hence, we examined whether CK-mediated induction of neurogenesis in the dentate gyrus is associated with BDNF and NT3 mRNA levels. Indeed, CK administration significantly increased the mRNA expression of BDNF and NT3 in the dentate gyrus of 2-mo and 24-mo mice. Interestingly, the mRNA levels of BDNF and NT3 in the CK-injected 24-mo mice were higher than 2-mo young mice. Previous studies show that the upregulation of BDNF and NT3 improves cognitive function in $\mathrm{AD}[35,36]$, suggesting that $\mathrm{CK}$ administration may be able to prevent cognitive impairment. Given that CK administration was sufficient to increase the BDNF mRNA level, we next investigated whether the overexpression of BDNF induced by CK administration could affect the phosphorylation of Akt and ERK1/2, which are downstream targets of the BDNF signaling cascade. In 2-mo and 24-mo mice, CK administration increased BDNF expression, which is consistent with the qRT-PCR results and the phosphorylation of Akt and ERK1/2. In particular, the BDNF protein level in 24-mo mice was lower than those in 2-mo mice (vehicle group) but CK administration was able to restore the BDNF protein up to the young mice level. The BDNF/Trkb signaling pathway has an essential role in the regulation of adult hippocampal neurogenesis [37]. Furthermore, the PI3K-Akt signaling pathway and activation of ERK1/2 signaling play a critical role in neuronal differentiation and in the survival of newly generated cells in the dentate gyrus [38-40], suggesting that CK-mediated activation of BDNF signaling contributes to increase the adult hippocampal neurogenesis in elderly mice (Figure 7).

\section{Conclusions}

In conclusion, the administration of CK resulted in an enhancement of adult hippocampal neurogenesis in both elderly and young mice. Therefore, ginsenoside compound $\mathrm{K}$ can become a therapeutic agent able to prevent age-related cognitive impairments due to reduced adult neurogenesis. Further studies are required to analyze the molecular mechanism by which compound $\mathrm{K}$ is able to induce BDNF transcription; promoter assay may help discovering the transcription factors involved in this CK-mediated induction of neurogenesis.

Author Contributions: Conceptualization, J-M.O., J.H.J., and S.C.; methodology, J-M.O., J.H.J., and S.Y.P.; resources, S.Y.P.; validation, J-M.O., J.H.J., S.Y.P., and S.C.; visualization, J-M.O. and S.C.; investigation, J.H.J., J-M.O., S.Y.P., and S.C.; writing—original draft preparation, J.H.J, J-M.O., and S.C.; writing-review and editing, J-M.O. and S.C., funding acquisition, S.C. All authors have read and agreed to the published version of the manuscript.

Funding: This work was supported by research funds from Basic Science Research Program (NRF-2017R1D1A1B03035125) through the National Research Foundation (NRF), which is funded by the Korean government; from Korea Health Technology R\&D project through the Korea Health Industry Development Institute (KHIDI), funded by the Ministry of Health \& Welfare, Republic of Korea (grant number: HI17C1510); and from Brain Pool Program through the National Research Foundation of Korea (NRF), funded by the Ministry of Science and ICT (NRF-2019H1D3A2A01059349).

Acknowledgments: We would like to thank Wan-Taek Im (Hankyung National University, Anseong, South Korea) for providing the ginsenoside Compound $\mathrm{K}$ and thank Editage (www.editage.co.kr) for English language editing.

Conflicts of Interest: The authors declare no conflict of interest.

\section{References}

1. Altman, J.; Das, G.D. Autoradiographic and histological evidence of postnatal hippocampal neurogenesis in rats. J. Comp. Neurol. 1965, 124, 319-335. [CrossRef] [PubMed]

2. Toda, T.; Parylak, S.L.; Linker, S.B.; Gage, F.H. The role of adult hippocampal neurogenesis in brain health and disease. Mol. Psychiatry 2019, 24, 67-87. [CrossRef] [PubMed]

3. Braskie, M.N.; Thompson, P.M. Understanding cognitive deficits in Alzheimer's disease based on neuroimaging findings. Trends Cogn. Sci. 2013, 17, 510-516. [CrossRef] [PubMed] 
4. Hoffman, J.D.; Parikh, I.; Green, S.J.; Chlipala, G.; Mohney, R.P.; Keaton, M.; Bauer, B.; Hartz, A.M.S.; Lin, A.L. Age Drives Distortion of Brain Metabolic, Vascular and Cognitive Functions, and the Gut Microbiome. Front. Aging Neurosci. 2017, 9, 298. [CrossRef]

5. Kuhn, H.G.; Dickinson-Anson, H.; Gage, F.H. Neurogenesis in the dentate gyrus of the adult rat: age-related decrease of neuronal progenitor proliferation. J. Neurosci. 1996, 16, 2027-2033. [CrossRef]

6. Mathews, K.J.; Allen, K.M.; Boerrigter, D.; Ball, H.; Shannon Weickert, C.; Double, K.L. Evidence for reduced neurogenesis in the aging human hippocampus despite stable stem cell markers. Aging Cell 2017, 16, 1195-1199. [CrossRef]

7. Winner, B.; Kohl, Z.; Gage, F.H. Neurodegenerative disease and adult neurogenesis. Eur. J. Neurosci. 2011, 33, 1139-1151. [CrossRef]

8. Varela-Nallar, L.; Aranguiz, F.C.; Abbott, A.C.; Slater, P.G.; Inestrosa, N.C. Adult hippocampal neurogenesis in aging and Alzheimer's disease. Birth Defects Res. 2010, 90, 284-296. [CrossRef]

9. Horgusluoglu, E.; Nudelman, K.; Nho, K.; Saykin, A.J. Adult neurogenesis and neurodegenerative diseases: A systems biology perspective. Am. J. Med. Genet. 2017, 174, 93-112. [CrossRef]

10. Encinas, J.M.; Michurina, T.V.; Peunova, N.; Park, J.H.; Tordo, J.; Peterson, D.A.; Fishell, G.; Koulakov, A.; Enikolopov, G. Division-coupled astrocytic differentiation and age-related depletion of neural stem cells in the adult hippocampus. Cell Stem Cell 2011, 8, 566-579. [CrossRef]

11. Gebara, E.; Sultan, S.; Kocher-Braissant, J.; Toni, N. Adult hippocampal neurogenesis inversely correlates with microglia in conditions of voluntary running and aging. Front. Neurosci 2013, 7, 145. [CrossRef] [PubMed]

12. Gil-Mohapel, J.; Brocardo, P.S.; Choquette, W.; Gothard, R.; Simpson, J.M.; Christie, B.R. Hippocampal neurogenesis levels predict WATERMAZE search strategies in the aging brain. PLoS ONE 2013, 8, e75125. [CrossRef] [PubMed]

13. Hasegawa, H.; Sung, J.H.; Matsumiya, S.; Uchiyama, M. Main ginseng saponin metabolites formed by intestinal bacteria. Planta Med. 1996, 62, 453-457. [CrossRef] [PubMed]

14. Yoon, S.H.; Han, E.J.; Sung, J.H.; Chung, S.H. Anti-diabetic effects of compound K versus metformin versus compound K-metformin combination therapy in diabetic db/db mice. Biol. Pharm. Bull. 2007, 30, 2196-2200. [CrossRef]

15. Chen, J.; Si, M.; Wang, Y.; Liu, L.; Zhang, Y.; Zhou, A.; Wei, W. Ginsenoside metabolite compound K exerts anti-inflammatory and analgesic effects via downregulating COX2. Inflammopharmacology 2019, 27, 157-166. [CrossRef]

16. Oh, J.M.; Kim, E.; Chun, S. Ginsenoside Compound K Induces Ros-Mediated Apoptosis and Autophagic Inhibition in Human Neuroblastoma Cells In Vitro and In Vivo. Int J. Mol. Sci. 2019, 20. [CrossRef]

17. Kim, E.; Kim, D.; Yoo, S.; Hong, Y.H.; Han, S.Y.; Jeong, S.; Jeong, D.; Kim, J.H.; Cho, J.Y.; Park, J. The skin protective effects of compound $\mathrm{K}$, a metabolite of ginsenoside Rb1 from Panax ginseng. J. Ginseng Res. 2018, 42, 218-224. [CrossRef]

18. Park, J.S.; Shin, J.A.; Jung, J.S.; Hyun, J.W.; Van Le, T.K.; Kim, D.H.; Park, E.M.; Kim, H.S. Anti-inflammatory mechanism of compound $\mathrm{K}$ in activated microglia and its neuroprotective effect on experimental stroke in mice. J. Pharmacol. Exp. Ther. 2012, 341, 59-67. [CrossRef]

19. Hou, J.G.; Xue, J.J.; Lee, M.R.; Sun, M.Q.; Zhao, X.H.; Zheng, Y.N.; Sung, C.K. Compound K is able to ameliorate the impaired cognitive function and hippocampal neurogenesis following chemotherapy treatment. Biochem. Biophys. Res. Commun. 2013, 436, 104-109. [CrossRef]

20. Zong, W.; Zeng, X.; Chen, S.; Chen, L.; Zhou, L.; Wang, X.; Gao, Q.; Zeng, G.; Hu, K.; Ouyang, D. Ginsenoside compound $\mathrm{K}$ attenuates cognitive deficits in vascular dementia rats by reducing the Abeta deposition. J. Pharmacol. Sci. 2019, 139, 223-230. [CrossRef]

21. Seo, J.Y.; Ju, S.H.; Oh, J.; Lee, S.K.; Kim, J.S. Neuroprotective and Cognition-Enhancing Effects of Compound K Isolated from Red Ginseng. J. Agric. Food Chem. 2016, 64, 2855-2864. [CrossRef] [PubMed]

22. Bologna-Molina, R.; Mosqueda-Taylor, A.; Molina-Frechero, N.; Mori-Estevez, A.D.; Sanchez-Acuna, G. Comparison of the value of PCNA and Ki-67 as markers of cell proliferation in ameloblastic tumors. Med. Oral Patol. Oral Cir. Bucal. 2013, 18, e174-179. [CrossRef] [PubMed]

23. Shohayeb, B.; Diab, M.; Ahmed, M.; Ng, D.C.H. Factors that influence adult neurogenesis as potential therapy. Transl. Neurodegener. 2018, 7, 4. [CrossRef] [PubMed]

24. Huang, E.J.; Reichardt, L.F. Neurotrophins: roles in neuronal development and function. Annu. Rev. Neurosci. 2001, 24, 677-736. [CrossRef] [PubMed] 
25. Vilar, M.; Mira, H. Regulation of Neurogenesis by Neurotrophins during Adulthood: Expected and Unexpected Roles. Front. Neurosci. 2016, 10, 26. [CrossRef]

26. Lazarov, O.; Mattson, M.P.; Peterson, D.A.; Pimplikar, S.W.; van Praag, H. When neurogenesis encounters aging and disease. Trends Neurosci. 2010, 33, 569-579. [CrossRef]

27. Moreno-Jimenez, E.P.; Flor-Garcia, M.; Terreros-Roncal, J.; Rabano, A.; Cafini, F.; Pallas-Bazarra, N.; Avila, J.; Llorens-Martin, M. Adult hippocampal neurogenesis is abundant in neurologically healthy subjects and drops sharply in patients with Alzheimer's disease. Nat. Med. 2019, 25, 554-560. [CrossRef]

28. Teixeira, C.M.; Pallas-Bazarra, N.; Bolos, M.; Terreros-Roncal, J.; Avila, J.; Llorens-Martin, M. Untold New Beginnings: Adult Hippocampal Neurogenesis and Alzheimer's Disease. J. Alzheimers Dis. 2018, 64, S497-S505. [CrossRef]

29. Van Praag, H.; Christie, B.R.; Sejnowski, T.J.; Gage, F.H. Running enhances neurogenesis, learning, and long-term potentiation in mice. Proc. Natl. Acad. Sci. USA 1999, 96, 13427-13431. [CrossRef]

30. Lee, J.; Seroogy, K.B.; Mattson, M.P. Dietary restriction enhances neurotrophin expression and neurogenesis in the hippocampus of adult mice. J. Neurochem. 2002, 80, 539-547. [CrossRef]

31. Scharfman, H.; Goodman, J.; Macleod, A.; Phani, S.; Antonelli, C.; Croll, S. Increased neurogenesis and the ectopic granule cells after intrahippocampal BDNF infusion in adult rats. Exp. Neurol. 2005, 192, 348-356. [CrossRef] [PubMed]

32. Quesseveur, G.; David, D.J.; Gaillard, M.C.; Pla, P.; Wu, M.V.; Nguyen, H.T.; Nicolas, V.; Auregan, G.; David, I.; Dranovsky, A.; et al. BDNF overexpression in mouse hippocampal astrocytes promotes local neurogenesis and elicits anxiolytic-like activities. Transl. Psychiatry 2013, 3, e253. [CrossRef] [PubMed]

33. Ockel, M.; Lewin, G.R.; Barde, Y.A. In vivo effects of neurotrophin-3 during sensory neurogenesis. Development 1996, 122, 301-307. [PubMed]

34. Shimazu, K.; Zhao, M.; Sakata, K.; Akbarian, S.; Bates, B.; Jaenisch, R.; Lu, B. NT-3 facilitates hippocampal plasticity and learning and memory by regulating neurogenesis. Learn. Mem. 2006, 13, 307-315. [CrossRef] [PubMed]

35. Blurton-Jones, M.; Kitazawa, M.; Martinez-Coria, H.; Castello, N.A.; Muller, F.J.; Loring, J.F.; Yamasaki, T.R.; Poon, W.W.; Green, K.N.; LaFerla, F.M. Neural stem cells improve cognition via BDNF in a transgenic model of Alzheimer disease. Proc. Natl. Acad. Sci. USA 2009, 106, 13594-13599. [CrossRef] [PubMed]

36. Nagahara, A.H.; Merrill, D.A.; Coppola, G.; Tsukada, S.; Schroeder, B.E.; Shaked, G.M.; Wang, L.; Blesch, A.; Kim, A.; Conner, J.M.; et al. Neuroprotective effects of brain-derived neurotrophic factor in rodent and primate models of Alzheimer's disease. Nat. Med. 2009, 15, 331-337. [CrossRef]

37. Li, Y.; Luikart, B.W.; Birnbaum, S.; Chen, J.; Kwon, C.H.; Kernie, S.G.; Bassel-Duby, R.; Parada, L.F. TrkB regulates hippocampal neurogenesis and governs sensitivity to antidepressive treatment. Neuron 2008, 59, 399-412. [CrossRef]

38. Bruel-Jungerman, E.; Veyrac, A.; Dufour, F.; Horwood, J.; Laroche, S.; Davis, S. Inhibition of PI3K-Akt signaling blocks exercise-mediated enhancement of adult neurogenesis and synaptic plasticity in the dentate gyrus. PLoS One 2009, 4, e7901. [CrossRef]

39. Jiang, P.; Zhu, T.; Xia, Z.; Gao, F.; Gu, W.; Chen, X.; Yuan, T.; Yu, H. Inhibition of MAPK/ERK signaling blocks hippocampal neurogenesis and impairs cognitive performance in prenatally infected neonatal rats. Eur. Arch. Psychiatry Clin. Neurosci. 2015, 265, 497-509. [CrossRef]

40. Tang, G.; Dong, X.; Huang, X.; Huang, X.J.; Liu, H.; Wang, Y.; Ye, W.C.; Shi, L. A natural diarylheptanoid promotes neuronal differentiation via activating ERK and PI3K-Akt dependent pathways. Neuroscience 2015, 303, 389-401. [CrossRef]

(C) 2020 by the authors. Licensee MDPI, Basel, Switzerland. This article is an open access article distributed under the terms and conditions of the Creative Commons Attribution (CC BY) license (http://creativecommons.org/licenses/by/4.0/). 